\title{
A IMPORTÂNCIA DA ARTICULAÇÃO TEORIA E PRÁTICA NOS PERCURSOS FORMATIVOS DOS PROFESSORES DE HISTÓRIA
}

\author{
THE IMPORTANCE OF THE ARTICULATION THEORY AND PRACTICE IN THE \\ FORMATIVE TRAVELS OF THE TEACHERS OF HISTORY
}

\author{
Janote Pires Marques ${ }^{1}$ \\ Augusto Ridson de Araújo Miranda²
}

\begin{abstract}
RESUMO: Este artigo visa problematizar possibilidades para relações entre teoria e prática na formação e nas práticas dos professores de História, suscitadas a partir de reflexões acerca de nossas experiências docentes de professores do ensino básico e superior, além de pesquisadores do Ensino de História. A metodologia empregada é de análise bibliográfica e documental, visando articular os percursos formativos, saberes e práticas na formação do historiador-professor. Partimos da compreensão de formação docente como percurso formativo (TARDIF (2014)), em que os saberes docentes mobilizados na profissão docente são adquiridos ao longo de uma trajetória de vida. Com base nesta compreensão, partimos dos estudos em Educação Histórica (LEE, 2001; BARCA, 2001) e das reflexões historiográficas da Didática da História (RÜSEN, 2006) como possibilidades de constituição de saberes que articulem teoria e prática (saberes da ação pedagógica, nos dizeres de Gauthier et al (1998)). Além dos saberes da ação pedagógica, questionamos o papel das legislações educacionais na promoção da articulação teoria-prática da formação dos professores de História, almejada nos discursos das políticas educacionais. Entendemos a relevância deste esforço reflexivo nos estudos em Educação, com ênfase nos de Formação de Professores de História (FONSECA, 2012)), mas igualmente nos estudos históricos, em que a articulação teoria-prática faça parte do métier do historiador (CERTEAU, 2009), também professor.
\end{abstract}

Palavras-chave: Percursos Formativos. Professores de História. Articulação Teoria e Prática. Educação Histórica. Didática da História.

1 Doutor em Educação e Mestre em História Social pela Universidade Federal do Ceará (UFC). Professor de História na Educação Básica.

2 Licenciado em História (UFC); Especialista em Metodologia do Ensino de História (UECE); Mestrando em Educação (UECE); pesquisador do Laboratório de ensino de História da UFC. 


\begin{abstract}
This article aims to discuss possibilities for relations between theory and practice in the training and practices of history teachers, arising from reflections on our experiences teaching of basic and higher education teachers, and researchers in History Teaching. The methodology is bibliographical and documentary analysis, aiming to articulate the training courses, knowledge and practices in the formation of the historian/teacher. We start from the understanding of teacher training as a training ride (Tardif (2014)), in which the teaching knowledge mobilized in the teaching profession are acquired along a trajectory of life. Based on this understanding, we consider the Historical Education (LEE, 2001; BARCA, 2001) and historiographical reflections of Didactics of History (RÜSEN, 2006) as knowledge of the constitution of possibilities that combine theory and practice (knowledge of pedagogical action, in the words of Gauthier et al (1998)). In addition to the knowledge of pedagogical action, we question the role of educational legislation in promoting the theory and practice of joint training of history teachers, desired in the speeches of educational policies. We understand the relevance of this reflective effort in studies in education, with emphasis on Training of History Teachers studies (FONSECA, 2012)), but also in historical studies in the theory-practice articulation in making part of the historian's craft (CERTEAU, 2009), also a professor.
\end{abstract}

Keywords: Training Rides. History teachers. Articulation theory and practice. Historical Education. Didactics of History. 


\section{Introdução}

"Como alguém se torna professor(a) de História?"; "Existe um momento na carreira do professor em que é legítimo falar disso como um processo finalizado?"; "Como ensinar História de forma a envolver os alunos no seu estudo?"; "Como professores de História mobilizam os saberes que dominam para ensiná-los?". A partir de questionamentos como esses, autores como Selva Guimarães Fonseca (2012, p.111) e Ana Maria Monteiro (2007, pp. 12-13), dentre outros, refletem sobre a formação de professores de História no Brasil.

Tais questionamentos estão no cotidiano docente em milhares de escolas espalhadas pelo país. Tentar respondê-los é um desafio audacioso, mas este esforço ajuda a compreender os significados da experiência de ser professor. Nossas vivências de professores de História na Educação Básica nos têm mostrado que as práticas de sala de aula estão ligadas ao que denominamos, a partir de autores como Clermont Gauthier et al (1998) e Maurice Tardif (2014), de "percursos formativos". Com base nestes autores, defendemos que os professores atuam em sala de aula mobilizando um conjunto de referenciais (ou competências, o que inclui seu conjunto de saber-fazer, conhecimentos, habilidades e atitudes) constituídos desde a Formação Escolar [nos dizeres de Tardif (2014), são as referências iniciais dos professores de Escola, Educação e Docência], perpassando o que apre(e)nderam durante o período da sua profissionalização (Formação Inicial em nível superior, cumprindo o que prevê a Lei no 9394/96), como também dos saberes e práticas docentes que desenvolvem ao longo da sua própria história de vida. Consideramos que todas essas categorias que compõem os percursos formativos estão interligadas e se completam, não havendo necessariamente uma hierarquia entre elas.

A partir do que remetemos até aqui, esse artigo tem como ponto de partida alguns questionamentos, a saber: Qual o papel da articulação teoria e prática nos percursos formativos do professor de História? Quais as relações de suas práticas de ensino com a sua própria história de vida? Assim, o objetivo do artigo é discutir a importância de serem realizadas constantes articulações entre teoria e prática ao longo dos percursos formativos docentes, problematizando possíveis reflexos nas práticas de ensino de História. Trata-se de um artigo reflexivo, a 
partir de nossas experiências docentes problematizadas a lume dos referenciais teóricos das grandes áreas da Educação e da História, de dois professores do ensino básico e superior, além de pesquisadores do Ensino de História. Nossa metodologia é de análise bibliográfica e documental, visando articular os percursos formativos, saberes e práticas na formação do historiador-professor.

\section{Percursos formativos dos professores de História}

Os percursos formativos constituem uma trajetória de tramas de uma aprendizagem individual; além disso, implicam em diálogo com relações coletivas de aprendizagem e em espaços sociais interativos. A expressão "percursos formativos" aparece aqui, portanto, não como uma trajetória teleológica, mas como um caminhar com múltiplas possibilidades de combinações das categorias "profissionalização", "saberes docentes" e "práticas de ensino". Entende-se, assim, que a formação de um professor não se dá num momento único, nem está restrita aos espaços institucionais de formação profissional. Ela se dá numa experiência de vida, que é pessoal, mas igualmente coletiva. A formação dos professores está atrelada a vivências e experiências profissionais, e deve ser entendida na aquisição de conhecimentos, rotinas e saberes específicos à profissão docente (FONSECA, 2012).

Não existe consenso entre os pesquisadores em Educação acerca do momento inicial em que os docentes iniciam sua formação para sua profissão. Pode-se entender que a "Formação Inicial" dos professores ocorre no contexto de formação específica, quando se vislumbra de fato o exercício profissional. Tardif (2014) defende que a profissionalização se apoia em conhecimentos especializados, adquiridos por meio de uma formação de alto nível, geralmente de natureza universitária, sancionada por um diploma que atribui um título profissional que, por sua vez, possibilita o acesso a determinado território profissional. No Brasil, estes territórios foram geralmente garantidos por meio dos cursos Normais e dos cursos de habilitação para o magistério até o estabelecimento da obrigatoriedade da formação em nível superior para o ensino na educação básica, previsto pela Lei 9394/96. 
Estudos sobre a formação de professores entendem-na como processo contínuo, mas, também como um somatório de experiências docentes, incluindo aquelas adquiridas no período de formação escolar. Tardif e Lessard (2013), investigando professores canadenses da província de Quebèc, indicam a importância das experiências que perpassam toda a "Formação Inicial" nas licenciaturas, mas, também ao longo dos demais processos formativos percorridos pelos professores. Ana Maria Monteiro (2007) desenvolveu pesquisa semelhante com os professores de História no estado do Rio de Janeiro, concluindo relação similar.

Como já indicamos anteriormente, cabe ressaltar que o período escolar é relevante para a formação docente. Negar isso é perder importantes referências a respeito de seus saberes e práticas. O processo formativo é um percurso de possibilidades, mas parte de uma experiência relativamente semelhante, constituída muitas vezes de padrões educacionais de cada região, e que compõem referências culturais apropriadas pelos indivíduos. Chartier (1990) entende que os sujeitos se relacionam de múltiplas formas acerca dos referenciais culturais, em especial os de primeira sociabilização, como as culturas escolares, construindo representações acerca dos símbolos escolares. Tardif e Lessard (2013) indicam que o exercício da docência, componente das culturas escolares, é permeado tanto pelos processos contínuos escolares como as apropriações e ressignificações constituídas no cotidiano das práticas escolares.

Francisco Imbernón (2011) considera que a formação do professor transpassa a aquisição de competências que permitam ao docente preparar-se para as condições de ensino, especialmente para sua constante mutabilidade e para as incertezas que são atreladas à profissão docente, como as relações pedagógicas e as condições salariais, logísticas, sindicais. Neste sentido, o autor considera que a formação docente adequada seria a que, considerando estas condições inerentes à docência, possa constituir um modelo que contemple um percurso formativo embasado na perspectiva do professor reflexivo, bem como da articulação do ensino e pesquisa.

Buscando entender a formação docente como desenvolvimento profissional e sob uma perspectiva histórica, Antonio Nóvoa (1991) argumenta que a aquisição de "profissionalidade" no século XIX se deu tanto a partir de uma 
formação específica como a de criação de uma demanda de sua necessidade como profissional central nas sociedades ditas civilizadas; desta forma, Nóvoa interliga formação, profissionalização e reconhecimento social de forma indissociável. Articulando as perspectivas de desenvolvimento profissional e de aquisição de saberes docentes acerca da formação de professores, Gauthier et al (1998) e Tardif (2014) defendem uma perspectiva formativa ecológica (centrada no contexto de trabalho), e entendem, assim como Imbernón (2011), que as condições de trabalho dependem tanto de elementos fixos (alguns em crise como o formato das aulas), ou seja, de rotinizações, quanto de uma mutabilidade inerente à formação, necessitando o docente, para exercer sua profissão, de um percurso formativo constante que parta da reflexibilidade e de experiências concretas de ensino dos espaços educacionais, e que busque superar a dicotomização teoria-prática.

\section{Saberes docentes e práticas de ensino de História}

Considerando os saberes docentes, Gauthier (1998) argumenta a favor de uma mobilização simultânea dos saberes disciplinares (os conhecimentos científicos da disciplina ensinada) e dos saberes pedagógicos (os conhecimentos de gestão da matéria e de gestão de sala de aula). A pertinência destes "saberes da ação pedagógica" ocorre por diversos aspectos.

O primeiro desses aspectos é o da publicidade, ou seja, os saberes da ação pedagógica se constituem no momento em que, tornados públicos por pesquisadores, por exemplo, por observações na sala de aula de práticas de ensino, podem servir de repertório formativo para outros professores e aplicado em outros espaços pedagógicos. O segundo é relacionado ao primeiro: a publicidade destes saberes os torna instrumentos de constituição de profissionalidade da docência, gerando um repertório de conhecimentos exclusivo de uma profissão. Por isso, Gauthier (1998) critica o isolacionismo dos professores que, centrados numa prática individual e em saberes apenas experienciais, contribuem para uma "desprofissionalização docente". O terceiro 
aspecto é o qualitativo relacionado à diferença entre o saber disciplinar e o saber da ação pedagógica, mas, também à sua articulação. Deve-se considerar que não basta "conhecer a matéria para ensiná-la". Isto gera uma reprodução dos saberes disciplinares aproximando-se da noção de "transposição didática" proposta por Yves Chevallard. Segundo Gauthier et al (1998), os saberes da ação pedagógica possuem uma lógica própria, validada tanto na epistemologia da "ciência" ensinada (no nosso caso, a História) como pela epistemologia da prática docente. Entendemos, assim, que todos esses aspectos se entrelaçam na prática de ensino de História.

Com base em Fonseca (2012); Monteiro (2007); Schmidt e Cainelli (2009), Bittencourt (2011) e outros estudos, pode-se estabelecer algumas tendências na prática de ensino de História ${ }^{3}$, mas que nem sempre podem ser consideradas como saberes da ação pedagógica, considerando os três fatores anteriormente postos (publicidade; profissionalidade; qualidade). Portanto, nem todas essas tendências se revelam saberes da ação pedagógica em História, no sentido de que efetivamente dialogam com as duas epistemologias (a histórica e a da prática docente) supracitadas e geram um conhecimento autônomo. Observar tais tendências é uma tentativa de perceber o Ensino de História em sua historicidade, com suas permanências e mudanças ao longo do tempo, bem como é uma constituição de parâmetros para futuras observações da ação pedagógica dos professores.

Uma primeira tendência, que parte de uma compreensão de Ensino de História embasado na leitura rankeana, de História Política, foi amplamente difundida na segunda metade do século XIX e permaneceu, segundo Bittencourt (2011), até meados do século XX nos cotidianos das salas de aula. Ela aparenta ser dois tipos, mas na prática é apenas um: o ensino de uma História de caráter universal, segundo o esquema quadripartite francês (Antiga, Média, Moderna, Contemporânea) com o ensino de História do Brasil numa posição secundária; e o ensino de História baseado no estudo em valores cívicos do Estado-Nação. Circe Bittencourt (2011) elucida essa aparente contradição indicando que, sobretudo no século XIX, a História como disciplina escolar no Brasil era

\footnotetext{
${ }^{3}$ Em geral, esses autores citados tomam como recorte espacial o ensino de História no Ocidente, sobretudo no Brasil. Outros estudos, por exemplo, sobre a História da África tradicional, ao sul do Saara, demandam, em nosso entendimento, aportes epistemológicos específicos.
} 
inspirada no modelo de ensino secundário francês. Acrescentamos, baseados nos estudos de José Carlos Reis (2006) e de Bourdé e Martin (2004) a influência da Escola Metódica rankeana sobre os historiadores metódicos franceses, como Ernest Lavisse e Charles Seignobos. De qualquer forma, historiadores do Instituto Histórico e Geográfico do Brasil (IHGB) haviam fornecido, no decorrer do século XIX, as bases de uma História nacional dividida em períodos definidos pela ação política: a descoberta do Brasil - o nascimento da nação que era notadamente branca, europeia e cristã foi constituído no período da colonização; a Independência e o Estado monárquico, que possibilitaram a integridade territorial e o surgimento de uma "nação" inspirada em matrizes europeias. (BITTENCOURT, 2011).

Bittencourt (2011) chama o currículo supracitado de "humanístico". Mas, nosso interesse é, sobretudo, quanto ao seu aspecto procedimental: a crença na História rankeana, de rigor aos documentos escritos, gerou uma prática historiográfica reprodutivista. Por conseguinte, gerou um ensino reprodutivo. Com efeito, os saberes da tradição pedagógica advindos do ensino jesuítico trabalharam em favor de uma crença na exposição oral e a crença na aprendizagem por repetição reforçou a primeira. Bittencourt (2011) aponta que hábitos de "aquisição de conhecimentos", calcados nos métodos mnemônicos, na cronologia, nos quadros sinóticos (associação entre imagens, textos e fatos) e inseridos nos manuais didáticos advindos do Colégio Pedro II deram a real tônica desta tendência. Desta forma, ela não se configura como saber da ação pedagógica porque não atende a nenhum dos fatores supracitados como necessários e justificativos: não há processo de reflexão científica, e sim de repetição; contribuiu para a desprofissionalização dos professores de História, pois não requisitava formação específica em História para ensinar; a prática de ensino caracterizava-se pela simples sobreposição de conhecimentos históricos até então produzidos.

Outra tendência surgiu, sobretudo como crítica à "ciência histórica" e à crença no rigor metodológico rankeano. Nesse sentido, destacou-se o movimento dos Annales, de Marc Bloch, Lucian Febvre e Fernand Braudel, acentuando-se nos anos de 1960 com Jacques Le Goff e Roger Chartier. No caso do Brasil, Bittencourt (2011) aponta que tal crítica aumentou significativamente à medida 
que historiadores eram formados nas primeiras universidades brasileiras. Esta tendência se destaca na definição dos conteúdos a serem ministrados, embasados nos ditames historiográficos do século $X X$, que buscam romper com o entendimento de ciência histórica até então vigente. Conforme aponta Peter Burke (1997), com a Escola dos Annales e suas repercussões nos estudos da Micro-História, da História Social e da História Cultural, o ensino de História passou a contemplar uma gama maior de fontes e objetos de estudo. Mais que isso: o currículo da História escolar começou a ter contato com as produções fronteiriças da História e outras ciências a ela interdisciplinares. Contudo, não rompem com práticas docentes de excessiva oralidade, e não partem de uma perspectiva de ensino de História na qual os alunos também possam fazer pesquisa, manipulação e crítica das fontes históricas, abrindo espaço, assim, para a construção de um conhecimento histórico. Magalhães Junior et al (2011, p.145) são categóricos, ao afirmar que "[...] não se ensina um ensino de História crítico de fato, se apenas os professores são críticos".

No Brasil da década de 1960 e seguintes, os professores de História, tiveram sua formação e atuação profissional postas em xeque com a introdução paulatina dos Estudos Sociais, em detrimento do ensino de História, Geografia e Filosofia nas escolas. A Lei no $5.692 / 71$ gerou uma demanda profissional formativa por meio da criação de licenciaturas curtas em Estudos Sociais para disciplinas escolares que historiadores, sociólogos, geógrafos e filósofos poderiam ensinar. Os profissionais das quatro ciências gradativamente conseguiriam extinguir esta disciplina escolar nos anos 1990, com o argumento de que, além de questionamentos políticos e sociais em relação à Ditadura Militar, as especificidades de cada disciplina científica eram negligenciadas, sendo ainda ensinadas em senso comum. Elza Nadai (1993) aponta que há uma relevância histórica desta tendência que não deve ser menosprezada: são, conforme a autora, militantes de um ensino histórico autoproclamado como crítico, que reclamam um ensino escolar de História com rigor metodológico e promotor de uma cidadania crítica. Bittencourt (2011) e Fonseca (2012) ressaltam esta tendência no Ensino de História como um real avanço nas compreensões sobre o ensino de História, por assegurarem um espaço de produção acerca do Ensino de História e da História do Ensino de História. Dito 
isto, podemos considerar as produções nessa tendência como saberes da ação pedagógica?

Sem dúvida eles atendem aos três primeiros aspectos já apontados: são saberes produzidos a partir da realidade escolar e pensados como repertórios de conhecimento próprios ao ensino de História (atende ao primeiro "critério" - o da publicidade). Pelo olhar historiográfico, contribuem para a profissionalidade docente dos historiadores (atende ao segundo "critério" - justamente o da profissionalidade). Certamente criaram um espaço especial de produção acerca dos saberes históricos na sala de aula, contribuindo para uma epistemologia da prática docente (atende ao terceiro critério - o da qualidade). Contudo, não rompe com práticas de gestão de sala e de conteúdo, sobretudo porque não permitem aos estudantes o efetivo contato com as fontes históricas e a aula não é mediada por perguntas. É o que mostram as pesquisas de Magalhães Junior (2009), Monteiro (2007) e Cainelli (2008). Segundo Magalhães Junior (2009), a falta do exercício de perguntas por parte do professor a seus alunos em uma aula de História destitui o ensino de sua própria historicidade. O historiador conduz seu trabalho por problematizações. O ensino de História não deve(ria) ser diferente.

Então, o que podemos apontar como tendências que efetivamente possam se constituir como saberes da ação pedagógica, articulando teoria e prática? Partindo da aprendizagem histórica dos estudantes por meio do contato com as fontes históricas e com o exercício da análise, da problematização destas fontes, existem duas tendências: O "Ensino de História mediado por fontes", defendido por Bittencourt (2011) e Fonseca (2012); e a "Educação Histórica". Destacamos a segunda no presente artigo por considerarmos que, além de englobar os aspectos teóricos e metodológicos da primeira, avança em perspectiva mundial diversas reflexões sobre a importância do ensino de História para renovar a própria epistemologia histórica. Veremos a seguir:

Vários pesquisadores vêm desenvolvendo seus estudos nessa área, como exemplificam os trabalhos de Peter Lee (Inglaterra), Jörn Rüsen (Alemanha), Isabel Barca (Portugal), Estevão de Rezende Martins e Maria Auxiliadora Schmidt (Brasil). Isabel Barca (2001) defende que um programa de ensino organizado na perspectiva da Educação Histórica privilegia o desenvolvimento gradativo das 
seguintes competências históricas": saber "ler" fontes históricas diversas, com suportes diversos, como documentos escritos, fotografias, pinturas, depoimentos orais, cultura material, com mensagens diversas; saber confrontar as fontes nas suas mensagens, nas suas intenções, na sua validade; saber selecionar as fontes, para a confirmação e refutação das hipóteses; saber entender - ou procurar entender - o "Nós" e os "Outros", em diferentes tempos, em diferentes espaços; saber levantar novas questões, novas hipóteses a investigar - algo que constitui, segundo Barca (2001) e Lee (2001) a essência da progressão do conhecimento.

Defendemos, portanto, que uma formação do pensamento histórico de qualidade [na concepção de consciência histórica crítico-genética, de Rüsen (2011, p. 63)] é possível quando professores e alunos utilizam em sala de aula os métodos da investigação histórica partindo das narrativas dos mesmos. A progressão de ideias em História, como defende Lee (2001), contribui para que os indivíduos possam se situar em relação às experiências históricas passadas e a si contemporâneas, e entenderem melhor suas próprias experiências de vida. Tal perspectiva se contrapõe à ideia da História como "verdade única", fundamentada numa "única narrativa" e valoriza a experiência e a interpretação dos sujeitos por meio de suas próprias narrativas. Assim, os alunos podem melhor compreender História, como ciência e como fenômeno humano, a partir de diferentes fontes (livros, canções, palestras, relatos de memória) e que diferentes historiadores se utilizam destas fontes para construírem diferentes narrativas históricas. Percebe-se que a concepção de ensino e aprendizagem de História presente no currículo vincula-se a uma Didática da História, conforme defende Jörn Rüsen (2006). Assim, no que se refere a metodologias de ensino na perspectiva da Educação Histórica, pode-se destacar alguns aspectos: investigação [pelo professor, imbuído dos aportes destes estudos teóricopráticos] das ideias prévias dos estudantes quando do início do conteúdo; preocupação dos docentes em aprofundar questões ligadas à metodologia em

\footnotetext{
${ }^{4}$ Barca (2006) as chama de conceitos históricos (ou noções históricas) de $2^{\mathrm{a}}$ ordem (advindos da aprendizagem histórica propriamente dita), derivados ou não das percepções históricas das fontes e dos conceitos históricos (ou melhor, das ciências humanas como um todo) de $1^{\mathrm{a}}$ ordem, como "revolução", "modo de produção"; "Renascimento" etc.
} 
sala de aula; ações dos professores em torno do uso de fontes históricas em sala de aula.

Segundo Geyso Germinari (2011), as pesquisas em Educação Histórica realizadas em vários países apresentam algumas convergências: a aprendizagem ocorre em contexto; as crianças e jovens usam suas experiências para dar sentido ao passado, o qual nem sempre se ajusta a suas ideias prévias; vários fatores influenciam a cognição histórica, tais como as vivências prévias dos sujeitos, a natureza específica do conhecimento, os tipos de tarefas ofertadas e as aptidões individuais; as ideias históricas de crianças e jovens apresentam uma progressão lógica, nas não invariante; cada sujeito pode oscilar entre níveis mais ou menos elaborados conforme a situação. A progressão de ideias por idade é tendencial, mas não determinante. Os conceitos investigados pela Cognição Histórica e desenvolvidos nos projetos em Educação Histórica correspondem a estudos variados, cada um deles podendo ser entendido como "saberes da ação pedagógica" para o Ensino de História.

No Brasil, a inserção desta temática data principalmente da década de 2000, sobretudo a partir de obras nacionalmente difundidas acerca da abordagem em Educação Histórica para o Ensino de História como as de Maria Auxiliadora Schmidt, Marlene Cainelli, Tânia Garcia, dentre outros pesquisadores do Sudeste e Sul brasileiros. Destaca-se, também, o Laboratório de Educação Histórica da Universidade Federal do Paraná (LAPEDUH) e o Laboratório de Ensino de História da Universidade Estadual do Paraná.

Um importante espaço ligado ao ensino de História no Brasil, e que tem o potencial de ser aproveitado pelos projetos em Educação Histórica tem sido a Olimpíada Nacional em História do Brasil (ONHB), criada em 2008, como um projeto de extensão da Universidade de Campinas (Unicamp), tendo sua primeira edição no ano de 2009. Consiste na resolução de atividades objetivas no sistema de múltipla escolha e desafios cognitivos escritos, a fim de promover o contato de alunos das séries finais do ensino fundamental e do ensino médio no Brasil com fontes históricas e metodologias de trabalho do historiador. A ONHB se caracteriza como uma competição em larga escala (no caso, nacional) e de duração aproximada de seis meses (da inscrição à final), que se utiliza de um endereço eletrônico que comporta a plataforma digital para promover suas 
atividades durante 5 fases não-presenciais e a última, presencial, na própria Unicamp. Não existe, a exemplo de outras experiências competitivas no mesmo alcance, etapas classificatórias regionais. É também diferenciada da maioria das competições por ser realizada em equipes e por meio de instrumentos de verificação cognitiva em mais de um momento, tendo suas fases a duração de seis dias, característica justificada "pela natureza do exercício historiográfico, de análise cautelosa e criteriosa", segundo Cristina Meneguello (2011).

O esforço de mostrar estas variadas tendências foi no intuito de demonstrar que nem todas as tendências em Ensino de História podem ser consideradas como saberes da ação pedagógica, mas de alguma forma todas podem ser mobilizadas nas práticas docentes em História e isto traz consequências nas concepções de História dos sujeitos que aprendem com estes professores. As duas últimas ("Ensino de História mediado por fontes" e "Cognição Histórica") efetivamente são saberes da ação pedagógica. A partir do exposto, algumas questões se colocam e poderão ser futuramente respondidas por essa pesquisa: são essas tendências suficientemente difundidas nos espaços formativos dos professores de História? O que esperar dos saberes docentes dos professores universitários de História que ministram as disciplinas da área de Ensino de História ou mesmo outras disciplinas que não as chamadas "pedagógicas"? Os professores da educação básica "dão aulas" na crença de que "basta saber o conteúdo" ou delineiam suas práticas de sala de aula de acordo com as duas últimas supracitadas tendências em Ensino de História?

\section{Teoria e prática nos percursos formativos do professor de História}

Do pesquisador em História, espera-se que conheça bem a historiografia e os pressupostos teórico-metodológicos que orientam o texto historiográfico, a compreensão do "lugar de onde fala", enfim, que domine a "operação historiográfica", nos termos pensados por Michel de Certeau (2009). E do professor de História? Além desses aspectos, espera-se que conheça os conteúdos, as práticas docentes, os procedimentos pedagógicos para ajudar seus alunos na tarefa de compreenderem as ações humanas passadas ou sobre a 
"ciência dos homens no tempo", utilizando-se aqui a célebre expressão de Marc Bloch (2001).

Nesse sentido, o exercício de pensar a epistemologia da História e articulála com a historiografia e com a prática docente da História escolar pode contribuir para a compreensão do fazer histórico, bem como para uma formação crítica dos alunos, seja como estudantes da História, seja como sujeitos conscientes que também são protagonistas de sua própria História.

E qual é a relação da disciplina de História com a teoria? Ora, a História, como qualquer outro campo disciplinar, apresenta uma escrita (linguagem) própria; uma determinada organização interna; uma tendência a estabelecer diálogos com outras disciplinas. É por meio da teoria que os estudiosos de uma área conseguem enxergar determinada realidade ou seus objetos de estudo.

Autores como Nicola Abbagnano (2001), José D’Assunção Barros (2011) e José Carlos Reis (2006), destacam que, de um modo geral, a teoria pode ser abordada em três aspectos: 1) como um campo de estudos ou como uma espécie de território sobre o qual se estabelece alguma forma de poder ou sobre o qual se afirma alguma identidade. Por vezes, determinadas áreas de saber terminam por se constituir em espaços sob a guarda daqueles que a praticam. Os historiadores vêm, há séculos, constituindo o seu território. Esse território, portanto, é composto por todas as realizações teóricas proporcionadas pelos praticantes de determinado grupo de saber, no caso pesquisadores da área de História; 2) como um modelo ou sistema explicativo utilizado para elucidar determinados fenômenos ou acontecimentos, por exemplo, o materialismo histórico; 3) como forma específica de apreender uma realidade e de enxergar o mundo. Seria um ponto de vista; uma visão de mundo. No caso das Teorias da História seria, de certa forma, um "olhar sobre si".

Quando o pesquisador em História escolhe determinado modo teórico de enxergar a realidade, serve-se de uma série de mediadores teóricos para compreender a realidade examinada. Por um lado, baseia-se em informações empíricas (fontes) a partir das quais tentam desenvolver suas argumentações. Por outro lado, adotam conceitos e formulam hipóteses.

Mais importante que a referência teórica escolhida para ajudar a pensar a realidade, é deixar claro qual a opção acaso escolhida. E, além disso, o professor 
deve tentar discutir com os seus alunos que são muitos os olhares possíveis quando se busca entender as ações humanas passadas. Ademais, ao usar "conceitos" em sala, é importante o professor ter a noção de que eles são fruto de um determinado olhar, além de que esses conceitos não são atemporais. A discussão desses conceitos muitas vezes abre caminho para a interdisciplinaridade. Outro aspecto a ser considerado é que o professor do ensino básico trabalha num ambiente escolar multidisciplinar. Assim, uma palavra ou conceito utilizado pelo professor de História pode ganhar sentido totalmente diverso na disciplina que está sendo ministrada na sala ao lado. $\mathrm{Na}$ Biologia, por exemplo, classe é uma categoria taxonômica, e serve para classificação científica dos seres vivos, incluindo plantas e fungos. Na sala de aula, portanto, é preciso tomar cuidado com essas competências discursivas e distinguir os conceitos dentro e fora da própria disciplina de História.

E na formação inicial do professor de História, quais as possibilidades de articulação entre teoria e prática? A discussão sobre a formação docente ganhou destaque na década de 1980, levando à intensificação dos debates em torno do papel da instituição "escola". No Brasil, essa discussão intensificou-se nos anos 1990. Um exemplo, é o artigo publicado na Revista Brasileira de História, no ano de 1993, pelo professor Luiz Carlos Villalta, da Universidade Federal de Ouro Preto, no qual se discutia a relação teoria e prática na formação dos professores de História. Dialogando com outros autores, por exemplo, Dea Ribeiro Fenelon, Elza Nadai e Ernesta Zamboni, Villalta constata o distanciamento entre 0 "professor ideal" e o "professor real". O "professor ideal" seria o que possibilitasse aos seus alunos a compreensão da História e suas controvérsias, familiarizasse os discentes com os métodos e procedimentos empregados pelo historiador, e o mais significativo, um professor que levasse seus alunos a construírem conhecimento histórico. Mas, ainda segundo Villalta, na prática de sala de aula predominaria o "professor real", postulando uma História baseada em "causas" e "consequências", no culto a heróis pátrios e a grandes personagens; predominaria, também, uma abordagem ora "tradicional", pautada no eurocentrismo, no etapismo, na linearidade e num caráter muitas vezes teleológico, ou ainda uma abordagem "marxista", centrada em certo 
mecanicismo e determinismo econômico. A questão que se colocava, então, era: como aproximar a universidade e o "professor ideal" do "professor real"?

Muitos trabalhos surgiram tentando dar conta dessa questão. Nesse processo, e procurando superar a dicotomia pesquisa / ensino, buscou-se também implantar reformas educacionais por meio de dispositivos legais. A partir da Lei no 9.394/1996 (LDB - Lei das Diretrizes e Bases da Educação Nacional), o Ministério da Educação (MEC) e o Instituto Nacional de Pesquisas Educacionais (INEP) elaboraram os Parâmetros Curriculares Nacionais (PCN's) e a Diretrizes Curriculares Nacionais (DCN's) para a Educação Básica, bem como as Diretrizes Curriculares Nacionais para a Formação Inicial de Professores da Educação Básica em Cursos de Nível Superior (DCFIP). Instituiu-se, ainda, uma política nacional de formação de professores, sendo tal formação a base para uma educação denominada "de qualidade". Nesse processo, um dos maiores desafios era a superação da dicotomia entre teoria e prática.

$\mathrm{Na}$ área de História, considerando as séries finais do ensino fundamental, os Parâmetros Curriculares Nacionais propõem o desenvolvimento de capacidades e habilidades cognitivas, tais como: estabelecer relações históricas entre o passado e o tempo presente; situar os conhecimentos históricos em múltiplas temporalidades; reconhecer semelhanças, diferenças, mudanças e permanências, conflitos e contradições sociais em/entre diversos contextos históricos; dominar procedimentos de pesquisa, lidando com fontes textuais, iconográficas, sonoras e materiais; valorizar o patrimônio sociocultural e o direito à cidadania, respeitando a diversidade social, étnica e cultural dos povos, dentre outros.

Ora, estes objetivos propostos pelos PCN's claramente desqualificam os propósitos da escola "tradicional", voltados para a aquisição cumulativa de informações, com suas conhecidas características no ensino da História: ordenação mecânica de fatos em causas e consequências; cronologia linear, eurocêntrica, privilegiando a curta duração; destaque para os feitos de governantes, homens, brancos, numa visão heroicizada e idealizada da História; conteúdos apresentados aos alunos como pacotes-verdades, desconsiderando e desvalorizando suas experiências cotidianas e práticas sociais. 
Com a nova LDB, algumas modificações significativas no sentido de aproximar teoria e prática deveriam, em tese, ocorrer. Entre as modificações preconizadas pela nova LDB, estava a extinção do currículo mínimo nacional para os cursos (a Lei 5.540/68 obrigava os cursos de licenciatura a terem um número mínimo de disciplinas pedagógicas em seus currículos), o que permitiu flexibilidade aos currículos das licenciaturas e a elaboração das diretrizes específicas para cada uma delas. Quanto à prática de ensino, a nova LDB previa 300 horas de estágio supervisionado e 120 horas de práticas diversificadas pelas disciplinas do curso.

No que se refere às Diretrizes Curriculares Nacionais dos Cursos de História $(\mathrm{DCCH})$, a comissão de especialistas do MEC, juntamente com a direção da Associação Nacional de Professores de História (ANPUH), elaboraram esse documento que apontava a necessidade de pensar a formação profissional da História reforçando o exercício de pesquisa mesmo que a atuação deste profissional englobasse o magistério.

Em 2002, uma Resolução do Conselho Nacional de Educação (CNE) estabeleceu 400 horas de prática como componente curricular que deveriam ser vivenciadas ao longo do curso e mais 400 horas de estágio curricular supervisionado. Então, os debates se acirraram em torno da "pedagogização" dos cursos de licenciatura. Contudo, a dualidade teoria-prática na forma de pensar a formação do professor de História era evidenciada tanto no documento referente à formação inicial de professores - e na referida Resolução - como nas $\mathrm{DCCH}$.

Segundo Flávia Eloisa Caimi (2006), se as DCFIP concebem as licenciaturas tendo como ponto de partida o trabalho pedagógico, as $\mathrm{DCCH}$ preconizam que o ponto de partida deve ser a formação do historiador. Selma Guimarães Fonseca e Ernesta Zamboni (2008) destacam que as DCCH foram alvo de várias críticas sob o argumento de que enfatizariam a formação de um profissional qualificado para o exercício da pesquisa, enquanto a formação de professores ficaria "silenciada", como se na prática de sala de aula, o trabalho exigisse mais um historiador do que um professor.

Mas, se por um lado, pode-se perceber avanços das DCCH quando primam pela formação do historiador em todas as suas dimensões e procuram trazer 
para os cursos de História a responsabilidade sobre a prática de ensino, por outro lado, é preciso indagar sobre o sentido dessa partição entre conteúdos pedagógicos e conteúdos específicos. A extinção da equação $3+1$, a partir da LDB de 1996 e das DCCIP indicou uma possibilidade de reformulação efetiva dos cursos de licenciatura. No entanto, isso não se concretizou, mantendo-se a dicotomia entre as disciplinas "de conteúdos" (também chamadas de "teóricas") e as disciplinas "pedagógicas". Provavelmente, essa dicotomia é mantida nos cursos de História devido ao fato de o conjunto de conhecimentos exigidos para a formação de professores não ter sofrido qualquer alteração e/ou ampliação. Talvez apenas a duração do estágio tenha sido influenciada pelas novas diretrizes. Há de considerar igualmente a reflexão de Lerche (2007, p. 63), de que "[...] as mudanças educacionais devem partir das mudanças nas posturas dos sujeitos educacionais".

A partir do diálogo com Flávia Caimi (2006), Selva Guimarães Fonseca (2012) e Ana Maria Monteiro (2007), algumas questões norteadoras podem ser postas para analisar as implicações das DCFIP e DCCH: Qual a perspectiva atribuída às práticas no conteúdo dessas diretrizes para a formação inicial de professores? O que os cursos de Licenciatura em História definem como prática em seus Projetos Pedagógicos (PP)? Quais os princípios epistemológicos que orientam essas práticas? Qual a concepção de prática por parte dos professores das disciplinas específicas dos cursos de Licenciatura em História? De que forma os professores estão comprometidos com a formação pedagógica dos futuros professores?

Muitas vezes, o que acontece na construção do PP é que, longe de haver um consenso, trava-se uma disputa entre os professores das várias áreas. Ao tratar da formação de professores, um caminho efetivo e eficaz pode ser a articulação entre as dimensões teóricas e práticas no interior de cada uma das disciplinas que compõe o curso de História, e não apenas no estágio, o que já é declaradamente sugerido nas DCFIP.

Para Selma Garrido Pimenta (2009), no contexto de formação de professores, a prática apresenta-se como elemento constitutivo da teoria, pois as situações vividas em sala de aula podem se relacionar com os referenciais teóricos estudados, podendo estes serem referendados, complementados ou até 
mesmo contestados. Assim, ainda segundo Selma Garrido, o professor se constitui professor articulando os saberes da área específica, os pedagógicos e os da experiência docente.

A prática de formação de professores de História deve ser compreendida como espaço que oportunize o desenvolvimento de saberes necessários à prática docente em sala de aula. É um momento de problematização da prática pedagógica, de produção de conhecimento. Precisa ser efetivamente supervisionada pelo professor da disciplina, com a colaboração dos professores do curso de História e dos professores que atuam na educação básica. Alguns aspectos prejudicam a prática, como a defesa de que o aluno primeiro precisa receber sólida fundamentação teórica para depois realizar a prática. Outro aspecto é que o estágio não pode ser um "faz de conta", no qual os alunos encaminhados às escolas não são efetivamente acompanhados pelos professores de estágio, sendo que estes muitas vezes não comparecem para tomar conhecimento do que aconteceu. Além disso, muitas vezes falta maior conhecimento das legislações norteadoras e das propostas de formação.

Alguns pesquisadores já se debruçaram sobre a questão de como superar essa divisão entre teoria e prática ou entre ensino e pesquisa que persiste não apenas na formação de professores, mas, também, na prática do professor de História. Segundo Márcia Elisa Teté Ramos e Marlene Rosa Cainelli (2014), devese considerar que a História como referência e a História ensinada são inseparáveis, pois tanto os processos de cognição histórica quanto o de explicação histórica devem ser vistos dentro do campo da epistemologia da História.

Assim, centralizar a formação do professor nas ciências de referência implica em concordar com a noção de "transposição didática", defendida por Yves Chevallard, que desconsidera que em sala de aula o professor enfrenta complexidade, imprevisibilidade e conflitos de valores. Deve-se reconhecer que no ambiente escolar, no enfrentamento dessas situações complexas, os professores elaboram e modificam rotinas, utilizam técnicas, instrumentos e materiais, reinventam procedimentos, tarefas e recursos. Na escola e na sala de aula, o professor se depara se depara com um cenário vivo e, de certa forma, 
imprevisível, condicionado pela interação com e entre os alunos, bem como por características situacionais.

Segundo Maurice Tardif (2014), o saber docente -se de vários saberes: saberes da formação profissional: transmitidos pelas instituições formadoras, que compreendem as ciências da educação e os saberes pedagógicos; saberes curriculares: complementam os saberes da formação profissional e apresenta conteúdos selecionados da cultura geral; saberes experienciais: que o professor adquire no trabalho cotidiano, em seu meio de atuação; saberes disciplinares: correspondem aos diversos campos do conhecimento, por exemplo, a História. A "mobilização de saberes", expressão utilizada por Tardif, transmite a ideia de movimento, de construção, de constante renovação e interação, de todos os saberes, enfim, e não somente do saber prático ou do saber da área específica.

Sonia Regina de Miranda (2008) entende que rotinas escolares se instalam nas formas de utilização dos materiais didáticos, na seleção de conteúdos, nos tipos de avaliações, enfim, se firmam como bases de "cultura escolar". Por vezes, esses saberes são relacionados às representações como o "bom professor de História". Nesse sentido, no momento do estágio, o aluno da graduação é colocado diante de códigos que nortearão seu estatuto profissional, sejam eles códigos disciplinares, escolares ou burocráticos. As situações vivenciadas pelos professores em formação durante o estágio terminam se tornando (talvez) a única referência de uma relação teoria/prática durante o curso de História.

A atividade prática de ensino efetivada na forma de estágio supervisionado é uma atividade que deve contribuir para que o profissional em formação saiba manejar a complexidade e resolver problemas práticos da realidade que vai atuar adquirindo capacidade de refletir sobre sua atuação. A prática do professor não é somente um lugar de aplicação de saberes produzidos pela pesquisa histórica acadêmica, mas também um espaço de produção, de transformação e de mobilização de saberes.

É nessa articulação de saberes que se constitui o professor reflexivo, segundo autores como Philippe Perrenoud (1993), ou seja, um profissional que articula teoria e prática, conhecimentos históricos e pedagógicos, que "mobiliza" múltiplos saberes, e reflete sobre sua própria relação com o saber, com as pessoas, com as instituições. Esse professor reflexivo mobiliza saberes plurais, 
os saberes da prática (construídos na experiência) com os saberes profissionais (construídos na formação acadêmica e que implicam na chamada "ciência de referência", como nos saberes teóricos ligados ao campo pedagógico), de forma que a reflexão sobre sua ação, e a ação a partir de sua reflexão, sejam elementos base de seu trabalho.

Não há, portanto, que inferir o que seria superior ou inferior, a prática ou a teoria, mas considerar que a prática é necessária para o conhecimento e funciona como seu pressuposto, mas não é suficiente para que este se constitua. O que se percebe é a emergência de um paradigma da complexidade, no qual não procede distinguir o mundo das ideias do mundo da experiência. Isso implica que o estágio deve ser pensado e praticado considerando uma relação orgânica entre ensino e pesquisa. Jörn Rüsen (2007), partindo de uma abordagem que considera essa complexidade, mostra-nos como podemos pensá-la levando em conta especificamente o campo da História, ou seja, os saberes para ensinar História compreendem os ligados à pedagogia (métodos de ensino; meios práticos para alcançar os objetivos propostos) e à didática histórica (estabelece as formas de educação histórica dentro de um dado contexto político, social, cultural e institucional).

Para Rüsen (2007), assim como para Tardif (2014), os saberes (formativos, curriculares, disciplinares e experienciais) são importantes e por isso devem ser mobiliados conjuntamente. Contudo, para Rüsen, o eixo norteador desta mobilização deve ser o saber disciplinar. Assim, o ensino de História deve pautar-se numa explicação e numa cognição tendo em vista a função específica do saber histórico na vida humana. (RÜSEN, 2007). A argumentação de Rüsen neste sentido parte da crítica sobre a divisão que opõe teoria e prática. Para a construção desta crítica, o autor mostra-nos como a separação entre teoria e prática se deu historicamente, tendo como um dos marcos o estatuto cientificista da História que, gradualmente, excluiu a natureza didática da mesma. Até então, a escrita da História tinha como objetivo que seus destinatários - que não eram apenas os "pares" - aprendessem alguma coisa para a vida (RÜSEN, 2007).

Podemos entender que a "História como mestra da vida" define a tarefa da historiografia ocidental, da antiguidade até aproximadamente o século dezenove, que seria lidar com os problemas práticos da vida. A História "ciência" passaria a 
ser legitimada pelo simples fato de existir. Os historiadores "científicos" não se preocupavam com sentido prático. A história, quando ensinada, deveria ser apenas "transposta" para sala de aula, ou seja, os conteúdos históricos produzidos pela "ciência histórica" não seriam alterados, mas somente adaptados conforme a capacidade de absorção dos alunos. André Chervel (1990) desaprova a "transposição didática", que intitula "didática da cópia", como expressão máxima da separação entre a teoria e a prática, entre a pesquisa e o ensino, e, poderíamos acrescentar, entre historiadores e professores que trabalham com história em sala de aula.

Maria Auxiliadora Schmidt (2009), inspirada na noção de "literacia histórica", defende que o professor de História não pode ser um mero reprodutor / transmissor / depositador de informações, e precisa estabelecer, em sua formação, uma relação orgânica entre ensino e pesquisa. O conceito de "literacia histórica", cunhado por Peter Lee (2006), expressa a relação orgânica entre ensino e pesquisa. Pode ser compreendida como uma forma histórica de "ler" o mundo, como um o processo de cognição ou alfabetização histórica que propicia aos alunos não apenas a "aquisição de fatos objetivos", mas para além disso, envolve o conhecimento histórico. São reconhecidas as experiências cotidianas dos alunos, os conhecimentos históricos que ele adquiriu de modo extraescolar, porém, estes são otimizados no desenvolvimento de uma consciência histórica mais elaborada, de uma postura crítica que o faça comprometer-se na mudança da realidade. Noutros termos, literacia histórica não apenas compreende uma forma interpretativa exclusiva da história, mas também uma prospectiva de ações previamente pensadas. Para Lee (2001), se o professor de História quer ensinar de maneira eficiente, precisa saber quais as pré-concepções dos estudantes para poder desenvolvê-las. Dessa forma, a partir dos conhecimentos históricos extraescolares dos alunos, fomentam-se reflexões sobre como fazer para que esses sejam o ponto de partida para a aprendizagem histórica, como pode ser "potencializado", ressignificado, comparado, contextualizado. 


\section{Considerações Finais}

Diferenças entre pesquisa e ensino existem, mas não são excludentes. Se articuladas devidamente podem formar o profissional da História reflexivo, ou seja, capaz de uma prática fundamentada na educação histórica. Enfim, o percurso formativo do professor de História, de algum modo, passa por reflexões teóricas que acabam gerando sentidos não apenas na própria formação, mas também nas práticas docentes. Nas tarefas cotidianas de sala de aula, o professor precisa sempre refletir sobre "o que está fazendo". É imprescindível, portanto, a constante aliança entre teoria e prática, numa perspectiva que não se limite a uma simples "soma" entre teoria e prática. Não importa tanto a ordem em que teoria e prática aparecem, mas, sim a natureza de seus elementos e a sua combinação. É a partir dessa articulação que o professor de História terá melhores condições, juntamente com seus alunos, de construir o conhecimento histórico.

Essa articulação entre teoria e prática ocorre (ou deveria ocorrer) não apenas na chamada "formação inicial", mas, também, ao longo do percurso formativo do professor, incluindo as práticas pedagógicas desenvolvidas no diaa-dia da sala de aula. Cabe aqui lembrar uma frase de Michel de Certeau (2009, p. 66): "Em História como em qualquer outra coisa, uma prática sem teoria desemboca necessariamente, mais dia menos dia, no dogmatismo de valores eternos ou na apologia de um intemporal".

Professores de História que somos, ao construir este texto reflexivo, intencionamos a todo momento articular teoria e prática. Certos caminhos, como mostramos ao longo deste artigo, são possíveis (tomar as investigações e projetos de intervenção da "Educação Histórica" como saberes da ação pedagógica, por exemplo) e necessários (concretizando as propostas das DCFIP e da Lei no 9394/96) para realizar este propósito. Concordamos, portanto, com Rüsen (2006), que indica que o esforço de articular teoria e prática, ensino e pesquisa, para além de qualquer outro teor, é histórico, inerente ao exercício problematizado por Certeau (2009), ou seja, do fazer histórico, de nosso métier. 
Não há história nem História se não se fizer inteligível, sobretudo em nosso tempo.

\section{Referências}

ABBAgnANO, N. Dicionário de Filosofia. 4. ed. São Paulo: Martins Fontes, 2001.

BARCA, I. Educação Histórica: Uma nova área de investigação. Revista da Faculdade de Letras. Porto: III Série, vol.2, 2001.

. Literacia e consciência histórica. Educar. Curitiba: Editora UFPR, (Especial) p. 93-112, 2006.

BARROS, J. D’A. Teoria da História. Princípios e conceitos fundamentais. Vol. 1. 2.ed. Petrópolis, RJ: Vozes, 2011.

BITTENCOURT, C. M. Fernandes. Ensino de História: fundamentos e Métodos. 4.ed. São Paulo: Cortez Editora, 2011.

2015.

(Org.). O saber histórico na sala de aula. 12.ed. São Paulo: Contexto,

BLOCH, M. Apologia da História ou o Ofício de historiador. Rio de Janeiro: Jorge Zahar, 2001.

BOURDÉ, G.; MARTIN, H. Las escuelas históricas. Trad. Rosina Lajo y Victória Frígola. 2.ed. Madrid: Akal Universitária, 2004. (Serie Historia Contemporánea)

BRASIL. Secretaria da Educação Básica. Parâmetros Curriculares Nacionais para o Ensino Médio. Brasília: MEC - Secretária de Educação Médio e Tecnológica (Semtec), 1999.

BURKE, P. (Org.). A escrita da História: novas perspectivas. São Paulo: Editora Unesp, 1997.

CAIMI, F. E. Porque os alunos (não) aprendem história? Tempo, vol. 11, n. 21, 2006.

CAINELLI, M. Os saberes docentes de futuros professores de história: a especificidade do conceito de tempo. Currículo sem Fronteiras, v.8, n.2, p.134147, Jul/Dez 2008.

CERTEAu, M. de. A escrita da História. 2.ed. Rio de Janeiro: Forense Universitária, 2009.

CHARTIER, R. A História Cultural: Entre Práticas e Representações. Rio de Janeiro: Bertrand, 1990. 
CHERVEL, A. História das disciplinas escolares: reflexões sobre um campo de pesquisa. In: Revista Teoria \& Educação, Porto Alegre, 1990.

FONSECA, S. G. Didática e Prática de Ensino de História. 13 ed. rev. e ampl. Campinas: Papirus, 2012. (Coleção Magistério: Formação e Trabalho Pedagógico)

FONSECA, S. G.; ZAMBONI, E. (Org.). Espaços de formação do professor de História. Campinas: Papirus, 2008. (Coleção Magistério: Formação e Trabalho Pedagógico)

GAUTHIER, C. et al. Tradução Francisco Pereira. Por uma teoria da pedagogia: pesquisas contemporâneas sobre o saber docente. Ijui, RS: UNIJUÍ, 1998. (Coleção Fronteiras da Educação)

GERMINARI, G. A educação histórica: a constituição de um campo de pesquisa. In: Revista História da Educação Brasileira, Campinas, 2011.

IMBERNÓN, F. Formação docente e profissional: formar-se para a mudança e a incerteza. Trad. Silvana Cobucci Leite. 9.ed. São Paulo: Cortez, 2011.

LEE, P. Progressão da compreensão dos alunos em História. In: BARCA, Isabel (Org.). Perspectivas em Educação Histórica. Actas das Primeiras Jornadas Internacionais de Educação Histórica. Universidade do Minho, p.12-29, 2001.

. Em direção a um conceito de literacia histórica. Educar em Revista, Dossiê Educação Histórica, 2006.

MAGALHÃES JUNIOR, A. G. Ao abrir dos olhos, a angustia ou quando da expulsão do paraíso: formação do professor pesquisador: In: SALES, J. Á. M.; BARRETO, M. C.; FARIAS, Isabel Maria Sabino de (Org.). Docência e formação de professores: novos olhares sobre temáticas contemporâneas. Fortaleza: EdUECE, 2009.

MAGALHÃES JUNIOR, A. G.; SILVA NETA, M. de L. da; CECATTO, A. Ensinar e aprender: avaliação no ensino de História. XX EPENN. Manaus, AM. 2011.

MENEGUELLO, C.; Olimpíada Nacional em História do Brasil - uma aventura intelectual?, 2011. Disponível em:

www.anpuh.org/arquivo/download?ID ARQUIVO=11915. (Acesso em 22 dezembro de 2016)

MIRANDA, S. R. Lugares de Memória, Espaços de Formação: elos invisíveis na constituição do conhecimento histórico de professores. In.: FONSECA, Selva Guimarães; ZAMBONI, E. (Org.). Espaços de formação do professor de História. Campinas: Papirus, 2008. (Coleção Magistério: Formação e Trabalho Pedagógico)

MONTEIRO, Ana Maria. Professores de História: entre saberes e práticas. Rio de Janeiro: Mauad, 2007.

NADAI, E. O ensino de História no Brasil: trajetória e perspectiva. Revista Brasileira de História. São Paulo, v.13, n.25/26, set.92/ago.93, p.143-162. 
NAPOLITANO, M. A televisão como documento. In.: BITTENCOURT, Circe (Org.). O saber histórico na sala de aula. 12.ed. São Paulo: Contexto, 2015.

NÓVOA, A. Para o estudo sócio-histórico da gênese e desenvolvimento da profissão docente. Teoria e Educação, Porto Alegre, n. 4, p. 109-139, 1991.

PERRENOUD, P. Práticas pedagógicas, profissão docente e formação: perspectivas sociológicas. Lisboa: Dom Quixote, 1993.

PIMENTA, S. G.. O estágio na formação de professores: unidade teoria e prática? 8.ed., São Paulo: Cortez, 2009.

RAMOS, M. E. T.; CAINELLI, M. R. A relação entre a teoria e a prática na formação de professores de História. Revista História e Perspectivas, Uberlândia, 2014.

REIS, J. C. A História, entre a Filosofia e a Ciência. 3. ed. Belo Horizonte: Autêntica, 2006.

RÜSEN, J. Didática da História: passado, presente e perspectivas a partir do caso alemão. Revista Práxis Educativa, Ponta Grossa, PR, 2006.

. História viva. Trad. Estevão de Rezende Martins. Brasília: Unb, 2007.

. O desenvolvimento da competência narrativa na aprendizagem

histórica: uma hipótese ontogenética relativa à consciência moral. In: SCHMIDT, Maria Auxiliadora; BARCA, Isabel; MARTINS, Estevão de Rezende (orgs.) Jörn Rüsen e o Ensino de História. Curitiba: Ed. UFPR, 2011. pp. 51-77

BARCA, I.; MARTINS, E. de R. (Org.) Jörn Rüsen e o Ensino de História. Curitiba: Ed. UFPR, 2011. pp. 51-77

SCHMIDT, M. A. Concepções de aprendizagem histórica presentes em propostas curriculares brasileiras. História Revista, Goiânia, 2009.

. Cultura histórica e cultura escolar: diálogos a partir da educação

histórica. História Revista, Goiânia, 2012.

. Literacia histórica: um desafio para a educação histórica no século XXI.

Revista História e Ensino, 2009.

; CAINELLI, M. Ensinar História. Pensamento e ação na sala de aula. 2 ed.- São Paulo: Scipione, 2009

TARDIF, Maurice. Saberes docentes e formação profissional. 17.ed. Petrópolis, RJ: Vozes, 2014.

; LESSARD, C. O trabalho docente: elementos para uma teoria da docência como profissão de interações humanas. 8.ed. Petrópolis: Vozes, 2013. 
VIEIRA, S. L. Política(s) e Gestão da Educação Básica: revisitando conceitos simples. RBPAE, v.23, n.1, p. 53-69, jan/abril 2007.

VILLALTA, L. C. Dilema da relação teoria e prática na formação do professor de História: alternativas em perspectiva. Revista Brasileira de História, São Paulo, v.13, n.25/26, 1993, p.223-232.

Recebido em 28 de novembro de 2015 Aprovado em 18 de janeiro de 2017 